\title{
Artificial Neural Networks (ANN) of Proposed Linear Induction Motor with Hybrid Secondary (HLIM) Considering the End Effect
}

\author{
Arash Mousaei ${ }^{1, ~ *, ~ N a s i m ~ B a h a r i ~}{ }^{1}$, Guo Mieho ${ }^{2}$ \\ ${ }^{1}$ Department of Electrical and Computer Engineering, University of Tabriz, Tabriz, Iran \\ ${ }^{2}$ Department of Electrical and Computer Engineering, University of Michigan, East Lansing, Michigan, USA \\ Email address: \\ a.mousaei97@ms.tabrizu.ac.ir (A. Mousaei),nasim_bahari@gmail.com (N. Bahari), gou.136m@mit.un.us (G. Mieho) \\ ${ }^{*}$ Corresponding author
}

\section{To cite this article:}

Arash Mousaei, Nasim Bahari, Guo Mieho. Artificial Neural Networks (ANN) of Proposed Linear Induction Motor with Hybrid Secondary (HLIM) Considering the End Effect. American Journal of Electrical and Computer Engineering. Vol. 5, No. 1, 2021, pp. 32-39.

doi: $10.11648 /$ j.ajece.20210501.15

Received: September 27, 2020; Accepted: June 22, 2021; Published: June 28, 2021

\begin{abstract}
Nowadays, linear electric motors are used in industries and applications that require linear motion. Different classifications for linear motors can be considered that one of them is based on their secondary. They have two secondary types: Flat (FLIM) and Ladder (LLIM) secondary. LLIMs have more thrust force than FLIMs, however due to their higher design cost, they are less popular. In this paper we proposed a linear induction motor with Hybrid (HLIM) secondary and its relationships with consideration of the end effect. Then, this motor optimally designed using the Particle Swarm Optimization (PSO) algorithm. Next its output speed is controlled by the Direct Thrust Force Control (DTFC) method. According to the results, speed of HLIM reaches the desired speed in less time than and also less ripple than LLIM and FLIM. Also HLIM has more power factor as well as more thrust force and more efficiency than LLIM and FLIM. Also HLIM has less design cost than the LLIM and FLIM.
\end{abstract}

Keywords: Linear Induction Motors (LIMs), Hybrid Secondary, Direct Thrust Force Control (DTFC), Particle Swarm Optimization (SPO)

\section{Introduction}

Linear Induction motors (LIMs) are a subset of electric machines, that linear speed and force are generated by magnetic fields and unlike rotary electric motors, do not require mechanical devices to convert rotary motion into linear motion. Linear motors have been of much interest to researchers over the past forty years and many articles have been written on their existing phenomena. In [1], a special Linear Induction Motor with Hybrid secondary (HLIM) is designed for Textile application. In [2], a LIM is controlled by an improved Direct Thrust Force Control (DTFC), where by optimizing the PI controller, its speed reaches reference speed with less ripple than the non-optimized mode.

The End-effect is one of the most important phenomena in LIM that effects the performance of the motor. In [3-10], this phenomenon is studied and parameters of the motor are obtained considering it. In [11], an equivalent circuit of $\pi$ shape is presented and the parameters of the motor are calculated. In $[12,13]$, the motor design and optimization are discussed with different optimization methods and considering different objective functions.

Mostly cites articles focused on Linear Induction Motors with Flat (FLIMs) secondary, while Linear Induction Motor with Ladder (LLIMs) secondary can be better in some applications. In [14], the End-effect in LLIM is studied. In [15], a special form of secondary bars is considered that improves the motor performance and increases its thrust force. In [16], a new method is presented for modelling a LLIM based on its magnetic equivalent circuit. In [17], with respect to the end effect, the linear induction motor is optimized and by oblique secondary bars the ripple flux density is reduced.

In [18], the Fuzzy Predictive Force Control (FPFC) for speed sensor less control of single-side Linear Induction 
Motor. The results showed that this control method has better performance in comparison to the conventional predictive control method. In [19], the MRAS strategy control is examined and Results indicated that the proposed adaptation mechanisms improve performance of MRAS speed estimator. In [20], a FPGA-based method is presented, where with the adaptive back stepping sliding-mode controller, the mover position of the FPGA-based LIM drive possesses the advantages of good transient control performance and robustness to uncertainties in the tracking of periodic reference trajectories.

Due to the above articles, has been less discussion about the DTFC method for HLIM. In this paper, we first reviewed, simulated, and optimized a HLIM using the Particle Swarm Optimization (PSO) algorithm [21], and its speed will be controlled by the DTFC and will be compared with two types of LLIM and FLIM. Then its output thrust force will be compared with two types of LLIM and FLIM. According to the results, the HLIM thrust force is more than FLIM and LLIM. Also, HLIM reaches the desired speed in less time than as well as less ripple than FLIM and LLIM. As well as according to the results HLIM has a higher power factor, higher thrust force and efficiency than LLIM and FLIM. MATLABC software is used to check the results.

\section{Relationship of HLIM, LLIM and FLIM}

Figure 1 shows LLIM and FLIM:

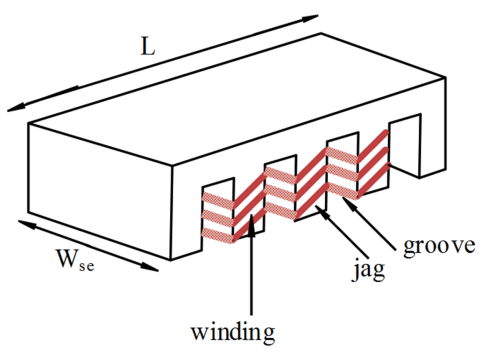

(a)

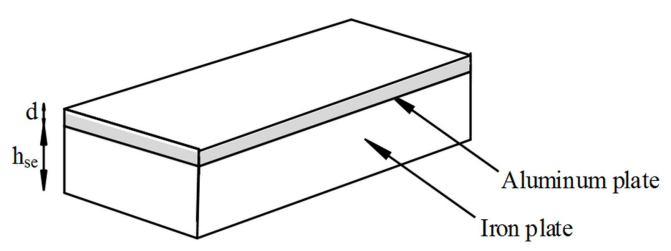

(b)

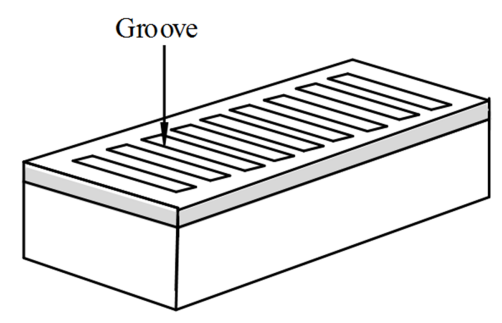

(c)

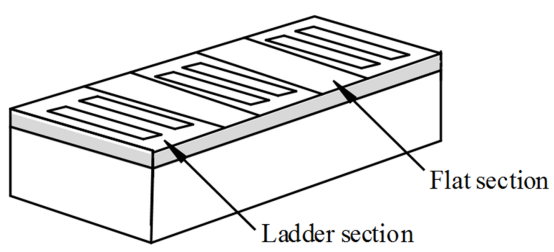

(d)

Figure 1. Linear Induction Motor: (a) Primary, (b) Flat, (c) Ladder, (d): Hybrid secondary.

In Figure 1 (a), $\mathrm{L}$ and $\mathrm{W}_{\mathrm{se}}$ are the primary length and the primary width, respectively. In Figure 1 (b) and Figure 1 (c), $d$ is the thickness of aluminum sheet and $h_{\text {se }}$ is the thickness of iron sheet. For both types of flat and ladder secondary induction motors, the values of primary resistance and reactance as well as magnetization reactance are equal. Primary resistance and reactance are obtained from the following equations [4]:

$$
\begin{gathered}
R_{1}=\rho \frac{2 N(L . W s e)}{A} \\
X_{1}=\frac{12.56 f \cdot N^{2}\left[\left(\lambda_{s}\left(1+\frac{3}{2 P}\right)+\lambda_{d}\right) \frac{W_{S e}}{q}+\lambda_{e} \cdot L\right]}{P}
\end{gathered}
$$

Where $\mathrm{N}$ is the number of primary coils, $\mathrm{A}$ is cross sectional of winding, $\rho$ is resistance of primary coils, $\mathrm{f}$ is frequency and $\mathrm{P}$ is the number of pole pairs. $\lambda_{\mathrm{s}}$ is the groove specific magnetic conductivity, $\lambda_{\mathrm{e}}$ is the magnetic conductivity of the end joints and $\lambda_{\mathrm{d}}$ is the differential magnetic conductivity also $\mathrm{q}$ is the number of grooves per motor phase that calculated as follows:

$$
\begin{aligned}
\lambda_{s} & =\mu_{0} \frac{h_{s}(1+3 \beta)}{12 W_{s e}} \\
\lambda_{e} & =0.3 \mu_{0}(3 \beta-1) \\
\lambda_{d} & =\mu_{0} \frac{5 g_{e i}}{5 W_{s e}+4 g_{e i}} \\
\lambda_{d} & =\mu_{0} \frac{5 g_{e i}}{5 W_{s e}+4 g_{e i}}
\end{aligned}
$$

Where $\beta$ is step of winding to step of polar, $g_{\text {ei }}$ is effective length of air gap, $h_{s}$ is depth of primary groove, $m$ is the number of phases and $\mathrm{z}$ is the total number of groove. Also for calculate the magnetization reactance, the following equation is used:

$$
X_{m}=\frac{37.7 f \mu_{0} W_{s e} K_{W}^{2} N^{2} \tau}{\pi^{2} P g_{e i}}
$$

Where $\mathrm{K}_{\mathrm{w}}$ is the coefficient of winding and calculated using following relations:

$$
\begin{gathered}
K_{w}=K_{p} K_{d} \\
K_{p}=\sin \left(\beta \frac{\pi}{2}\right) \\
K_{d}=\frac{\sin \left(q \frac{\alpha}{2}\right)}{q \sin \left(\frac{\alpha}{2}\right)}
\end{gathered}
$$

Where $\alpha$ is the electric angle of the groove in terms of electrical degree and we have: 


$$
\alpha=\frac{2 \pi P}{z}
$$

For resistance of secondary in FLIM we have:

$$
R_{2 F L I M}=\frac{6 W_{S e} K_{W}^{2} N^{2}}{P \tau \sigma_{e i} d}
$$

That $\sigma_{\mathrm{ei}}$ is the secondary conductivity that equivalent to:

$$
\sigma_{e i}=\frac{\sigma}{k_{s k} k_{t r}}+\frac{\sigma_{i} \delta_{i}}{k_{t r i} d}
$$

Where $\mathrm{k}_{\mathrm{sk}}$ is coefficient of secondary conductivity, $\mathrm{k}_{\mathrm{tri}}$ is coefficient of iron conductivity due to the edge effect, $\delta_{\mathrm{s}}$ and $\delta_{\mathrm{i}}$ are the depth of field penetration in aluminum and secondary iron, respectively, obtained from the following equations:

$$
\begin{gathered}
k_{s k}=\frac{d}{\delta_{s}}\left[\frac{\sinh \left(\frac{2 d}{\delta_{s}}\right)+\sinh \left(\frac{2 d}{\delta_{s}}\right)}{\cosh \left(\frac{2 d}{\delta_{s}}\right)-\cosh \left(\frac{2 d}{\delta_{s}}\right)}\right] \\
k_{s k}=\frac{d}{\delta_{s}}\left[\frac{\sinh \left(\frac{2 d}{\delta_{s}}\right)+\sinh \left(\frac{2 d}{\delta_{S}}\right)}{\cosh \left(\frac{2 d}{\delta_{s}}\right)-\cosh \left(\frac{2 d}{\delta_{s}}\right)}\right] \\
\delta_{i}=\operatorname{Re}\left[\frac{1}{\sqrt{\left(\frac{\pi}{\tau}\right)^{2}+j \frac{\omega \mu_{r i} \mu_{0} s}{k_{t r i}}}}\right] \\
\delta_{s}=\frac{1}{\sqrt{\frac{1}{2}\left(\frac{\pi}{\tau}\right)^{2}+\mu_{0} \pi f s \sigma}}
\end{gathered}
$$

That $\sigma$ is the secondary aluminum conductivity, $\sigma_{i}$ is the secondary iron conductivity, $\mathrm{k}_{\mathrm{tr}}$ is a constant coefficient that depends on the motor quality, and $\mu_{\mathrm{ri}}$ is the relative magnetic permeability coefficient of the secondary iron.

In FLIM, secondary inductance can be ignored. In the other words:

$$
X_{2 F L I M} \approx 0
$$

In LLIM the secondary resistance will be as follows:

$$
R_{2 L I M}=\frac{W_{s e} N^{2} K_{w}^{2} \tau_{2} A_{s}}{P \tau d W_{2} \sigma}\left(1+A_{e}\right)
$$

Where $\tau_{2}$ is the secondary groove step, $A_{s}$ is the cross-sectional of the secondary groove. $A_{e}$ is a coefficient of resistance between the secondary grooves and obtained from the following relation:

$$
A_{e}=\frac{R_{S 2}}{2 R_{b} \sin ^{2}\left(\frac{\pi P}{N_{l}^{2}}\right)}
$$

Where $R_{2}$ is the resistance of between of ladder, $R_{b}$ is the resistance of ladder, and $\mathrm{N}_{1}$ the number of grooves in the secondary. Also in LLIM, the secondary reactance is not zero and calculated as follows:

$$
X_{2}=150.8 \mu_{0} W_{s e} N_{l} K_{w}^{2} f\left(\lambda_{s 2}+\lambda_{e 2}+\lambda_{d 2}\right)
$$

That $\lambda_{\mathrm{d} 2}, \lambda_{\mathrm{e} 2}$ and $\lambda_{\mathrm{s} 2}$ are the differential magnetic conductivity, end connections conductivity and the secondary groove conductivity, respectively [15].
According to the mentioned relations, for secondary resistance and reactance of proposed HLIM, we will have:

$$
\begin{gathered}
R_{2 H L I M}=G R_{2 F L I M}+H R_{2 L L I M} \\
X_{2 H L I M}=G X_{2 F L I M}+H X_{2 L L I M}
\end{gathered}
$$

Where $\mathrm{G}$ and $\mathrm{H}$, are Flat section and Ladder section length, respectively.

\section{Dynamic Model of HLIM}

In order to obtain the HLIM model in a d-q reference frame, first the stator voltage equation should be introduced:

$$
\begin{gathered}
U_{d s}=R_{1} i_{d s}+R_{2 H L I M} f(Q)\left(i_{d s}+i_{d r}\right)+\frac{d \lambda_{d s}}{d t}-\omega_{e} \lambda_{q s} \\
U_{q s}=R_{1} i_{q s}+\frac{d \lambda_{q s}}{d t}+\omega_{e} \lambda_{d s} \\
U_{d r}=R_{2 H L I M} i_{d r}+\frac{d \lambda_{d s}}{d t}-\left(\omega_{e}-\omega_{r}\right) \lambda_{q s} \\
U_{q r}=R_{2 H L I M} i_{q r}+\frac{d \lambda_{q r}}{d t}+\left(\omega_{e}-\omega_{r}\right) \lambda_{d r} \\
\lambda_{d s}=L_{1} i_{d s}+L_{m}(1-f(Q))\left(i_{d s}+i_{d r}\right) \\
\lambda_{q s}=L_{1} i_{q s}+L_{m}\left(i_{q s}+i_{q r}\right) \\
\lambda_{d r}=L_{2 H L I M} i_{q r}+L_{m}(1-f(Q))\left(i_{d s}+i_{d r}\right) \\
\lambda_{q r}=L_{2 H L I M} i_{q r}+L_{m}\left(i_{q s}+i_{q r}\right) \\
f(Q)=\frac{1-e^{-Q}}{Q} \\
Q=\frac{(n G+m H)}{V L_{2 H L I M}} R_{2 H L I M}
\end{gathered}
$$

In the above relationships, $\mathrm{n}$ is number of flat sections and $\mathrm{m}$ is number of ladder sections. According to relationships (5), (6) and (16) we have:

$$
Q=\frac{(n G+m H)\left(G R_{2 F L I M}+H R_{2 L L I M}\right)}{V\left(G L_{2 F L I M}+H L_{2 L L I M}\right)}
$$

After solving the above relationship, we have:

$$
\begin{aligned}
\frac{d Q}{d t}=- & \frac{1}{V^{2}\left(G L_{2 F L I M}+H L_{2 L L I M}\right)}\left(n G^{2} R_{F L I M}+n H R_{L L I M}+\right. \\
& \left.m H G R_{F L I M}+m H^{2} R_{L L I M}\right) \frac{d V}{d t}
\end{aligned}
$$

\section{Optimization and Design}

The Particle Swarm Optimization (PSO) algorithm [21] is used to design and optimize the motor. In this algorithm, arbitrary inputs are first given and based on the condition that we place at the end of the algorithm, equivalent circuit parameters of motor are design and obtained. Here, first, inputs such as voltage, frequency, rated speed and rated slip are considered. Then, according to the following algorithm, the required outputs for the motor design are calculated: 


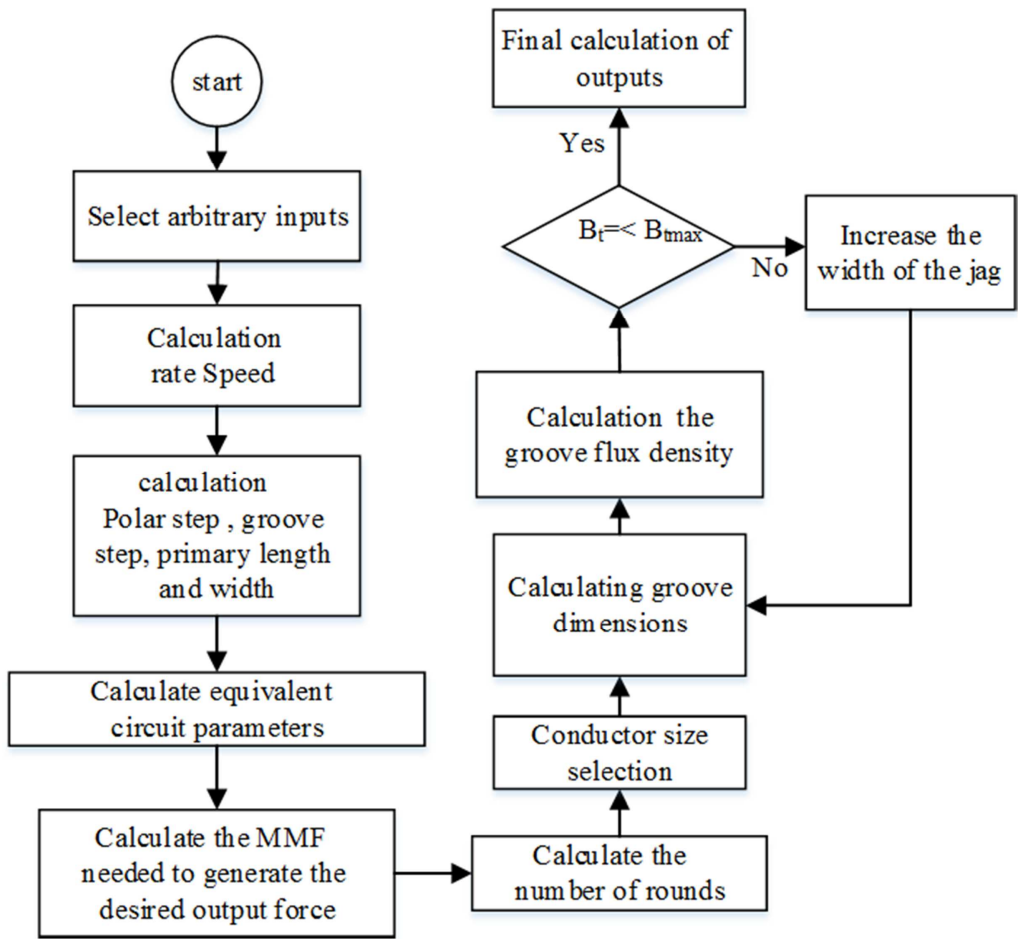

Figure 2. Block Design of Optimization Algorithm.

The following table shows the rated inputs for FLIM and LLIM:

Table 1. Rated motor Input Values.

\begin{tabular}{ll}
\hline Specifications & Amounts \\
\hline voltage $(\mathrm{V})$ & 220 \\
thrust force $(\mathrm{N})$ & 30 \\
frequency $(\mathrm{Hz})$ & 50 \\
speed $(\mathrm{m} / \mathrm{s})$ & 2 \\
slip & 0.2 \\
voltage $(\mathrm{V})$ & 220 \\
thrust force $(\mathrm{N})$ & 30 \\
\hline
\end{tabular}

According to the values of table 1 and the proposed algorithm, the optimal values for the design of the linear induction motor are given in the following tables. Various variables can be considered to optimize the design. The following table values are obtained with consider the output power, speed and efficiency of the motor as objective function:

Table 2. Output values for optimal design of HLIM.

\begin{tabular}{ll}
\hline Specifications & Amounts \\
\hline effective air distance & $3.21 \mathrm{~mm}$ \\
number of pair poles & 2 \\
iron secondary thickness & $15.9 \mathrm{~mm}$ \\
primary length & $0.629 \mathrm{~m}$ \\
secondary length & $0.8 \mathrm{~m}$ \\
secondary groove Width & $5.2 \mathrm{~mm}$ \\
primary groove width & $5.5 \mathrm{~mm}$ \\
frequency & 50 \\
number of rounds & 316 \\
number of grooves in each phase at each pole & 3 \\
primary width & $106.48 \mathrm{~mm}$ \\
secondary width & $130.73 \mathrm{~mm}$ \\
secondary jag Width & $8.3 \mathrm{~mm}$ \\
Primary jag width & $3 \mathrm{~mm}$ \\
m & 51 \\
primary groove depth & $34.17 \mathrm{~mm}$ \\
$\mathrm{H}$ & $7.74 \mathrm{~mm}$ \\
\hline
\end{tabular}




\section{Direct Thrust Force of HLIM}

In the Direct Thrust Force Control (DTFC) method, speed and stator voltage of motor are calculated by the sensor [2]. Then by relationships (36-40), the flux linkage, $\theta$ and thrust force are estimated. Next, compared with real and reference value of the flux linkage and thrust force. Then they are passed through the hysteresis controllers. Then using the switching table for selection the inverter's switch on and off to provide the demand voltage. Figure 3 shows the DTFC method.

Table 3. Switch table.

\begin{tabular}{|c|c|c|c|c|c|c|c|}
\hline \multicolumn{2}{|c|}{ Error status of } & $\theta(1)$ & $\theta(2)$ & $\theta(3)$ & $\theta(4)$ & $\theta(5)$ & $\theta(6)$ \\
\hline \multirow{3}{*}{$\lambda=1$} & $\mathrm{~T}_{\mathrm{e}}=1$ & 2 & 3 & 4 & 5 & 6 & 1 \\
\hline & $\mathrm{T}_{\mathrm{e}}=0$ & 0 & 7 & 0 & 7 & 0 & 7 \\
\hline & $T_{e}=-1$ & 6 & 1 & 2 & 3 & 4 & 5 \\
\hline \multirow{3}{*}{$\lambda=0$} & $\mathrm{~T}_{\mathrm{e}}=1$ & 3 & 4 & 5 & 6 & 1 & 2 \\
\hline & $\mathrm{T}_{\mathrm{e}}=0$ & 7 & 0 & 7 & 0 & 7 & 0 \\
\hline & $\mathrm{T}_{\mathrm{e}}=-1$ & 5 & 6 & 1 & 2 & 3 & 4 \\
\hline
\end{tabular}

$$
\begin{gathered}
F_{e}=\frac{3 p \pi}{4 \tau} \cdot \frac{L_{m}(1-f(Q))}{L_{2 H L I M}-H_{m} f(Q)}\left(\lambda_{d r} i_{q s}-L_{2 H L I M} \frac{f}{1-f} i_{q s} i_{d s}=m \frac{d V}{d t}+B V+F_{L}\right. \\
\lambda_{d s}=\int\left(U_{d s}-R_{1} i_{d s}-R_{2 H L I M} f(Q) i_{d s}\right) d t \\
\lambda_{q s}=\int\left(U_{q s}-R_{1} i_{q s}\right) d t \\
\lambda_{q s}=\sqrt{\lambda_{d s}^{2}+\lambda_{q s}^{2}} \\
\theta=\tan ^{-1}\left(\frac{\lambda_{q s}}{\lambda_{d s}}\right)
\end{gathered}
$$

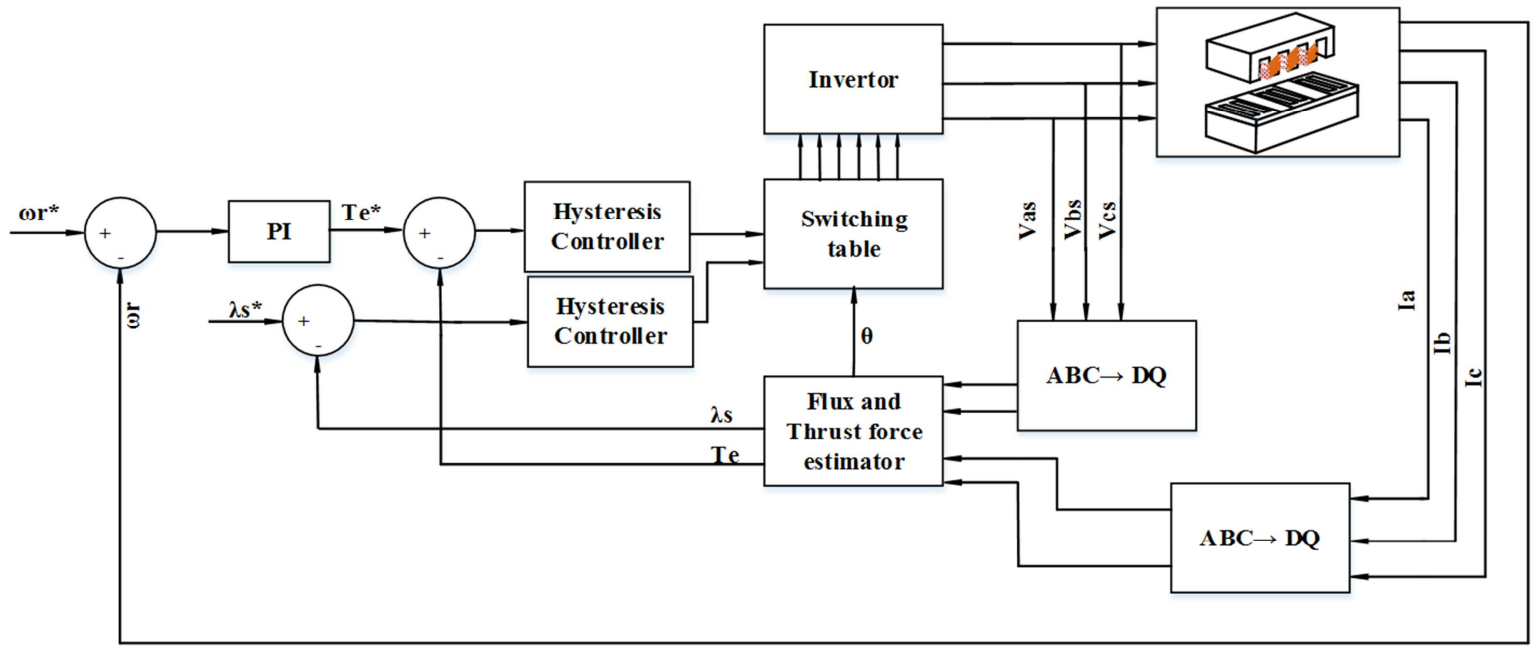

Figure 3. Block diagram of DTFC.

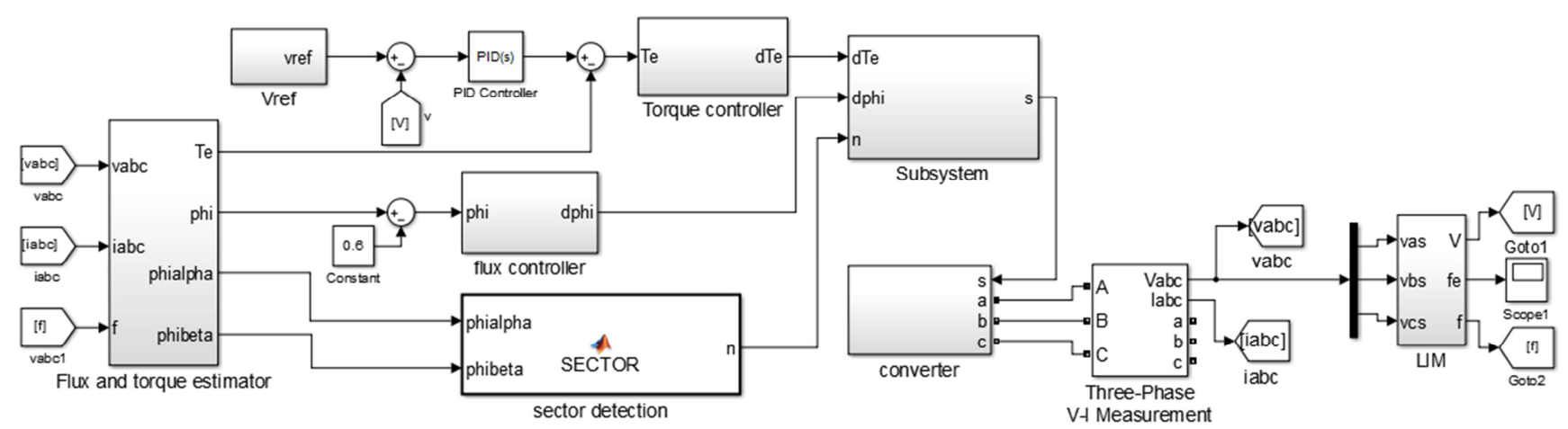

Figure 4. Simulink model of DTFC for HLIM with End effects. 


\section{Simulation Results}

In this section, simulation results of HLIM, LLIM and FLIM will be presented. The main aim of this paper is control of HLIM by the DTFC method. For this purpose, the reference value of LIM speed is selected $2 \mathrm{~m} / \mathrm{s}$ that is equal to $7.2 \mathrm{~km} / \mathrm{h}$. For values of FLIM and LLIM, we have used the PSO algorithm and optimized them. This values listed in the tables 4 and 5.

Table 4. Output values for optimal design of LLIM.

\begin{tabular}{ll}
\hline Specifications & Amounts \\
\hline width of Primary jag & $4 \mathrm{~mm}$ \\
Primary groove width & $5.7 \mathrm{~mm}$ \\
Groove depth & $21.3 \mathrm{~mm}$ \\
Groove width to step ratio & 0.6365 \\
Secondary iron thickness & $14.6 \mathrm{~mm}$ \\
Motor length & $0.3 \mathrm{~m}$ \\
Number of secondary bars & 218 \\
Secondary groove Width & $4.3 \mathrm{~mm}$ \\
Frequency & 50 \\
Effective air distance & $2.5 \mathrm{~mm}$ \\
Number of pair poles & 2 \\
Number of turns & 316 \\
Number of grooves in each phase at each pole & 4 \\
Primary width & $68.3 \mathrm{~mm}$ \\
Secondary jag width & $7.14 \mathrm{~mm}$ \\
\hline
\end{tabular}

Table 5. Output values for optimal design of LLIM.

\begin{tabular}{ll}
\hline Specifications & Amounts \\
\hline Jag width & $4 \mathrm{~mm}$ \\
Groove width & $7.3 \mathrm{~mm}$ \\
Groove depth & $30.1 \mathrm{~mm}$ \\
Groove width to step ratio & 0.7 \\
Secondary iron thickness & $15.9 \mathrm{~mm}$ \\
Motor length & $0.251 \mathrm{~m}$ \\
Frequency & 50 \\
Air gap & $2.72 \mathrm{~mm}$ \\
Number of pair poles & 2 \\
Number of turns & 267 \\
Number of grooves in each phase at each pole & 3 \\
Primary width & $67.21 \mathrm{~mm}$ \\
\hline
\end{tabular}

Figures 5 to 7 show HLIM, LLIM and FLIM respectively. Speed of HLIM achieving reference speed in $0.247 \mathrm{sec}$ and with $0.04 \%$ ripple and speed of LLIM in $0.466 \mathrm{sec}$ and $0.74 \%$ ripple, reaches the desired speed. Also speed of FLIM reaches the desired speed in $0.618 \mathrm{sec}$ and with $0.76 \%$ ripple.

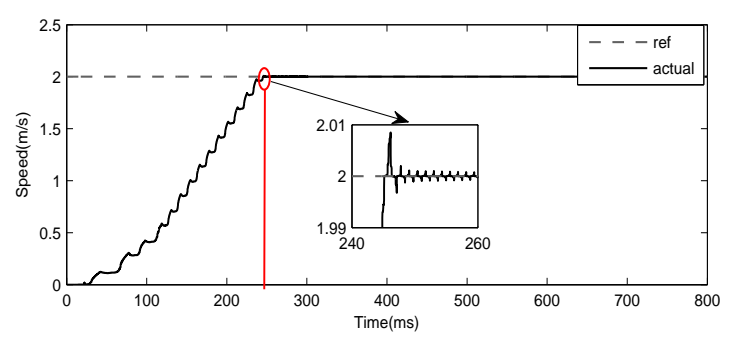

Figure 5. Linear speed of HLIM.

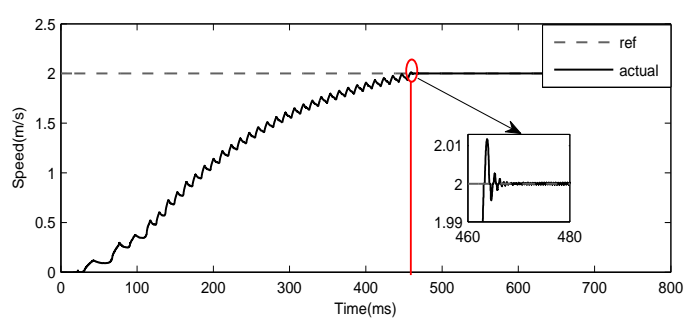

Figure 6. Linear speed of LLIM.

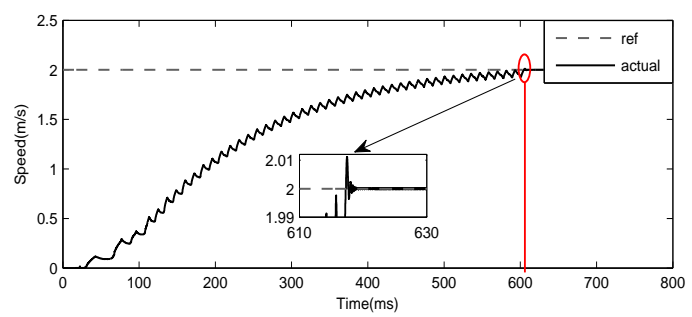

Figure 7. Linear speed of FLIM.

Using Equations (36-40) and according to Figures 7 to 9, HLIM, LLIM and FLIM can produce 33.4, 27.8 and $25.1 \mathrm{~N}$, respectively. Also these values obtained in the duration of $5.18 \mathrm{~ms}$ for HLIM, $10.4 \mathrm{~ms}$ for LLIM and $15.72 \mathrm{~ms}$ for FLIM.

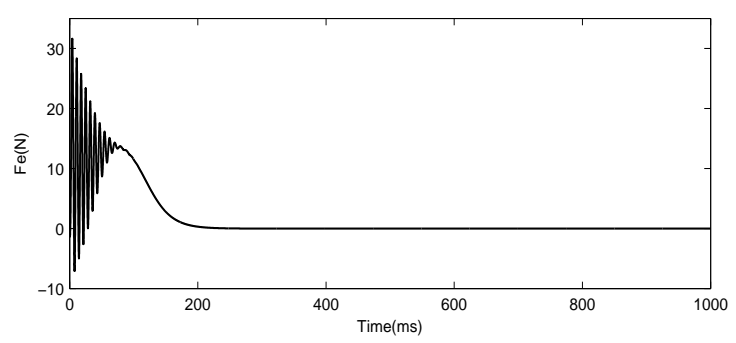

Figure 8. Thrust force of HLIM.

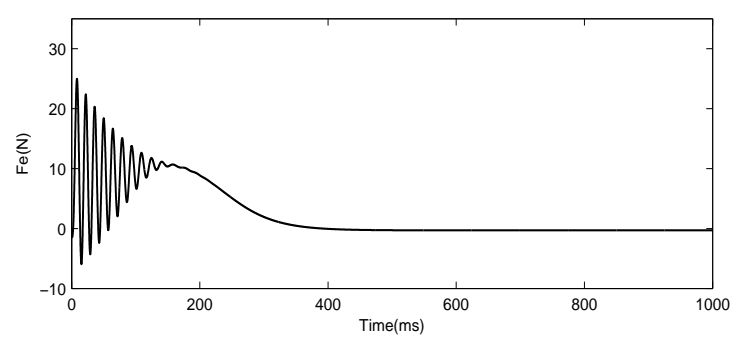

Figure 9. Thrust force of LLIM.

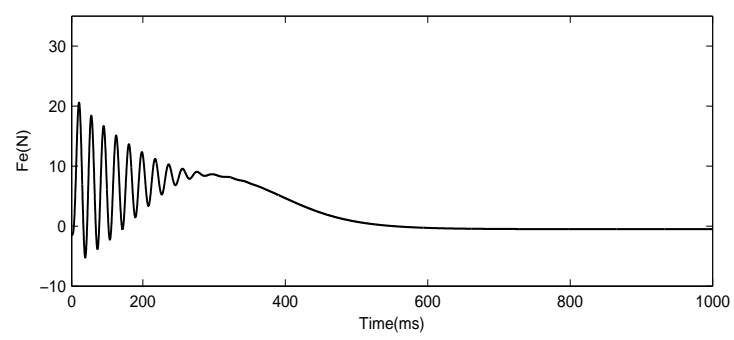

Figure 10. Thrust force of FLIM. 
As well as by equations (24) to (35), we can calculate current of HLIM, LLIM and FLIM. Also in the LIMs, the braking force $\left(F_{b}\right)$, efficiency $(\eta)$ and power factor $(\cos \varphi)$ are obtained by the following equations $[3,6]$ :

$$
F_{b}=\frac{3 R_{2 L I M}\left(i_{d s}+i_{d r}\right)^{2}}{2 f \tau}
$$

$$
\begin{gathered}
\eta=\frac{F_{e} V}{2 f\left(F_{e}+F_{b}\right)+3 R_{1} i_{d s}^{2}} \\
\cos \varphi=\frac{2 f \tau\left(F_{e}+F_{b}\right) R_{1} i_{d s}^{2}}{U_{d s}}
\end{gathered}
$$

The above relationships have used for HLIM, LLIM and FLIM and the results are given in Table 6.

Table 6. Outputs of HLIM, LLIM, FLIM.

\begin{tabular}{lllll}
\hline & Thrust Force (N) & Braking force (N) & Efficiency (\%) & Power factor \\
\hline FLIM & 25.1 & 0.32 & 54.2 & 0.463 \\
LLIM & 27.8 & 0.91 & 65.8 & 0.527 \\
HLIM & 33.4 & 1.12 & 72.3 & 0.618 \\
\hline
\end{tabular}

\section{Conclusions}

The Linear Induction Motors with Ladder secondary (LLIMs) have more Thrust Force than Linear Induction Motors with Flat secondary (FLIMs). However due to their higher design cost, they are less popular. In this paper we proposed a Linear Induction motor with Hybrid (HLIM) secondary and its relationships with consideration of the end effect. Then, this motor optimally designed using the Particle Swarm Optimization (PSO) algorithm. Next its output speed is controlled by the Direct Thrust Force Control (DTFC) method. According to the results, speed of HLIM reaches the desired speed in less time than and also less ripple than LLIM and FLIM. Also HLIM has more power factor as well as more thrust force and more efficiency than LLIM and FLIM. Also HLIM has less design cost than the LLIM and FLIM.

\section{References}

[1] A. Mousaei and M. B. B. Shrifian, "Design and optimization of a Linear Induction Motor with hybrid secondary for textile applications", The 28th IEEE Iranian Conference on Electrical Engineering, Tabriz, Iran, 26-28 May. 2020.

[2] H. Shadabi, A. Rahnama Sadat, A. Pashaei, M. M. B. Sharifian, "Speed Control of Linear Induction Motor Using DTFC Method Considering end-effect Phenomenon", International Journal on Technical and Physical Problems on Engineering, vol. 6, no. 4, pp. 75-81, Dec, 2014.

[3] K. Yamazaki, "Modification of 2D nonlinear time-stepping analysis by limited 3D analysis for induction machines", IEEE Transactions on Magnetics, vol. 33, no. 2, pp. 1694-1697, Mar. 1997.

[4] A. Shiri and A. Sholai, "Linear Induction Motor, Analysis, Design and Modeling", Shahid Rajaee University Press Education, Fall 2016.

[5] E. Amiri and E. Mendrela, "A novel equivalent circuit model of linear induction motors considering static and dynamic end effects", IEEE Transactions on Magnetics, vol. 50, no. 3, pp. 120-128, Mar. 2014.

[6] E. R. Laithwaite and S. A. Nasir "Linear-motion electrical machines" Proceedings of the IEEE, vol. 58, no. 4, April 1970.

[7] A. Shiri and A. Shulaie, "Design optimization and analysis of single-sided linear induction motor, considering all phenomena", IEEE Transactions on Energy Conversion, vol. 27, no. 2, June 2012.

[8] H. Yu and B. Fahimi, "Effects of air gap length variation in frictionless linear induction transportation system", IEEE Vehicle Power and Propulsion Conference, 2007, pp. 377-382.

[9] A. Shiri and D. E. Moghaddam, "A new dynamic model for linear induction motors, considering end effect", The $10^{\text {th }}$ International Symposium on Linear Drives for Industry Applications (LDIA), Aachen, Germany, pp. 27-29, July 2015.

[10] K. Woronowicz and A. Safaee, "A novel linear induction motor equivalent circuit with optimized end effect model", Canadian Journal of Electrical and Computer Engineering, vol. 37, pp. 34-41, 2014.

[11] F. Sarapulov, S. Sarapulov and I. Smolyanov, "Compensated linear induction motor characteristics research by detailed magnetic equivalent circuit", International Conference on Industrial Engineering, Applications and Manufacturing (ICIEAM), 2017.

[12] A. Zare-Bazghale, M. Naghshan and A. Khodadoost, "Derivation of equivalent circuit parameters for single sided linear induction motor", IEEE Transactions on plasma Science, vol. 43, no. 10, pp. 3637-3644, Sep. 2015.

[13] A. H. Isfahani, H. Lesani, and B. Ebrahimi, "Design optimization of a low-speed single-sided linear induction motor for improved efficiency and power factor", IEEE Transactions on Magnetics, vol. 44, pp. 266-272, June 2008.

[14] M. Hofmann, A. Binder and R. Pfeiffer, "Investigations on a linear induction machines for railway applications", Electric Machines and Drives Conference, Cambridge, MA, USA, 2001.

[15] N. Fuji and T. Harada, "A new viewpoint of end effect of linear induction motor from secondary side in ladder type model", IEEE Transactions on Magnetics, Vol. 35, No. 5, Sep. 1999.

[16] T. Yamaguchi, M. Ito and K. Matusi, "Improvement of thrust of linear induction motor using modified ladder slits", IEEE Power Conversion Conference, vol. 35, 2, pp. 563-566, 1997.

[17] P. Naderi and A. Shiri, "Modeling of ladder-secondary linear induction machine using magnetic equivalent circuit", IEEE Transactions on Vehicular Technology, 2018.

[18] M. Masoumi Kazraji, et al, "Fuzzy Predictive Force Control (DTFC) for Speed Sensorless Control of Single-side Linear Induction Motor", International Journal on Engineering, Technology \& Applied Science Research, vol. 7, no. 6, pp. 2132-2138, 2017. 
[19] M. H. Holakooie, et al, "MRAS based Speed Estimator for Sensorless Vector Control of a Linear Induction Motor with Improved Adaptation Mechanisms", Journal on power electronics, vol. 15, no. 56, pp. 1274-1285, Sep, 2015.

[20] F. J. Lin, et al, "FPGA-based Adaptive Backstepping Sliding-Mode Control for Linear Induction Motor Drive", IEEE Transactions on power electronic, vol. 22, no. 4, Juy, 2007.

[21] J. Kennedy and R. C. Eberhart, "Partical Swarm Optimization", Proceeding of IEEE International Conference on Neural Networks, Piscataway, NJ, pp. 1942-1948, 1995.

[22] K. Aditya, A. Newwel, et al, "Implementation of Close Loop Speed Control with VVVF Control and Slip Regulation on LIM", International Journal on Engineering, Technology \& Applied Science Research, vol. 4, no. 2 pp. 596-599, 2014.

[23] B. Laporte and N. Takorabet, "An approach to optimize winding design in linear induction motors", IEEE Transactions on Magnetics, vol. 33, no. 2, pp. 1844-1847, Mar. 1997.

[24] M. Rosenmayr, A. Glavitsch and H. Stemmler, "Swissmetro Power supply for a high power propulsion system with short stator linear motor", 15th International Conference on Magnetically Levitated System and Linear Drives Maglev, Yamanashi, Japan, pp. 280-286, 1998.

[25] G. Lv, D. zeng and T. Zhou, "An advanced equivalent circuit model for linear induction motor", IEEE Transactions on Industrial Electronics, vol. 65, pp. 7495-7503, Feb. 2018.
[26] G. Lv, D. zeng and T. Zhou, "Intluence of the ladder-slit secondary on reducing the edge effect and transvers forces in the linear induction motor", IEEE Transactions on Industrial Electronics, vol. 65, pp. 7516-7525, Sep. 2018.

[27] A. Shiri, "Electromagnetics force analysis in linear induction motors, considering end effect", The 7th IEEE Conference on Power Electronics, Drive system and Technologies Conference, Tehran, Iran, 16-18 Feb. 2016.

[28] G. Kang and K. Nam, "Field-oriented control scheme for linear induction motor with the end effect", IEEE Proc. On Power Electric applications, vol. 152, no. 6, pp. 1565-1572, November 2015.

[29] T. L. Bergman, A. S. Lavine, D. P. Dewitt, and F. P. Incropera, "Introduction to heat transfer", John Wiley \& Sons, 6th Edition, USA, 2011.

[30] A. Shiri, "Electromagnetic force analysis in linear induction motors, considering end effect", 7th Power Electronics, Drive Systems \& Technologies Conference (PEDSTC), Iran University of Scinence and Technology, Tehran, Iran, Feb. 2016.

[31] R. W. Burns, "Charles Wheatstone FRS 1802-1875 (2nd edition)", IET Engineering Science and Education, vol. 11, no. $5,2002$.

[32] E. R. Laitwaite, "Induction machines for special purposes", Chemical Publishing Company, Inc, New York, 1966. 